Full length article

\title{
Different $\beta$-glucans improve the growth performance and bacterial resistance in Nile tilapia
}

\author{
Fabiana Pilarski ${ }^{a}$,, Carlos Alberto Ferreira de Oliveira ${ }^{\text {b }}$, \\ Fernanda Patrícia Brito Darpossolo de Souza ${ }^{b}$, Fábio Sabbadin Zanuzzo ${ }^{a}$ \\ a São Paulo State University, Aquaculture Center of Unesp, Jaboticabal, Via de Acesso Prof. Paulo Donato Castelane, 14.884-900, Jaboticabal, São Paulo, Brazil \\ b Department of Research and Development, Biorigin Company, Fazenda São José s/n, 17290-000, Macatuba, São Paulo, Brazil
}

\section{A R T I C L E I N F O}

Article history:

Received 31 January 2017

Received in revised form

21 June 2017

Accepted 26 June 2017

Available online 27 June 2017

\section{Keywords:}

Fish

Prebiotics

Immunostimulant

Glucans

\begin{abstract}
A B S T R A C T
The role of glucan as a biologically active immunomodulator has been well documented for more than 40 years. However, the wide diversity of $\beta$-glucan forms and the extraction process has implications for the benefits of these compounds. Biorigin developed two samples of $\beta$-glucans using different biotechnological processes. Thus, in the present study, we fed Nile tilapia (Oreochromis niloticus) diets containing these two $\beta$-glucan molecules (BG01 and BG02) for 30 days prior to bacterial infection with Streptococcus agalactiae. The results showed that the different $\beta$-glucan samples exhibited biologically differently behaviors, but both increased the resistance against bacterial infection. Specifically, BG01 increased immunostimulation, while BG02 improved growth performance. In summary, these findings confirm the benefits of $\beta$-glucans in aquaculture and also provide further evidence of the growth promotion of these compounds.
\end{abstract}

(c) 2017 Elsevier Ltd. All rights reserved.

\section{Introduction}

Recently increasing attention has been focused on the use of functional dietary supplements, such as probiotics, prebiotics and immunostimulants, in aquaculture [1,2]. These compounds are beneficial for improving the immune status, feed efficiency and growth performance in fish [3]. Among these feed additives, $\beta$ glucans exhibit tremendous potential for use in aquaculture industry, as these compounds reduce stress, disease outbreaks, and fish product development through biotechnical approaches [3,4].

'Glucans' is the common name given to a group of polysaccharide polymers, classified based on interchain linkages as either $\alpha$ - or $\beta$-linked. These compounds are widely distributed in bacteria, algae, fungi and plants, with different structural types (see Barsanti et al. [5]). The common structure comprises a main chain of $\beta$-(1,3)- and/or $\beta$ - $(1,4)_{-}$-glucopyranosyl unit in non-repeating but non-random order, with side chains of varying lengths [6]. $\beta$ glucans from all sources have been variously demonstrated to have pro- or anti-inflammatory effects on immune cells, and the recognition of these compounds likely depends on the cell types

\footnotetext{
* Corresponding author.

E-mail address: fabianap@caunesp.unesp.br (F. Pilarski).
}

involved and the receptor(s) engaged [7]. According to Brown and Gordon [8], the effects of $\beta$-glucans on the immune response depend on the molecular weight and degree of branching. Larger molecular weight glucans activate the innate immune response, while short, low molecular weight glucans are inactive [9].

Indeed, these structural differences could also affect the extraction of $\beta$-glucan, and in turn, affecting the immunostimulatory activity of these molecules [6]. Even $\beta$-glucans from the same species and sources can behave biologically differently when extracted and purified through different processes. Considering this knowledge, and with an extensive background in $\beta$-glucan extraction technology, the Research Center of Biorigin developed two insoluble $\beta$-glucan samples using different biotechnological methods. Thus, the present study evaluated the effects of the two different $\beta$-glucan molecules on the growth performance and bacterial resistance of Nile tilapia, an important worldwide freshwater species.

\section{Material and methods}

\subsection{Experimental animals}

A total of 126 (initial weight $188.1 \pm 2.9 \mathrm{~g}$ ) juvenile Nile tilapia were obtained from the Toca da tilapia fish farm (Arealva, SP, 
Brazil). The fish were randomly separated into 6 fiberglass tanks (500 1; 21 fish per tank) and initially fed a commercial diet at $2 \%$ of their body mass twice a day. The tanks were supplied with water flow-through at $26 \pm 1{ }^{\circ} \mathrm{C}$ and a photoperiod of $14 \mathrm{~h}$ light: $10 \mathrm{~h}$ dark. The oxygen levels $\left(>5.0 \mathrm{mg} \mathrm{l}^{-1}\right)$ were monitored. The fish were maintained under these conditions for at least 2 weeks prior to the experiment.

\subsection{Experimental design: the effects of $\beta$-glucan on stress, bacterial resistance and growth performance}

After acclimation, the fish were fed three experimental diets (see diet preparation below, Table 1 ): control diet without $\beta$-glucan, diet supplemented with $0.1 \mathrm{~g} \mathrm{~kg}^{-1}$ BG01 or diet with $0.1 \mathrm{~g} \mathrm{~kg}^{-1}$ BG02. Additional information about the $\beta$-glucan samples can be found in supplemental Table 1 . After feeding for 30 days, the blood was drawn from 10 fish per tank ( 2 tanks per diet, $n=20$ ) through caudal puncture and the body weight was measured. Thereafter, the remaining fish received an intraperitoneal injection of Streptococcus agalactiae (see preparation below) and were subsequently sampled at $8 \mathrm{~h}$ after injection $(\mathrm{n}=20)$. The fish were continuously monitored and mortality recorded daily. The fish sampled prior to infection were also intraperitoneally injected with S. agalactiae and placed into individual tanks/treatment. Both groups were used for the assessment of the survival rate. We measured plasma glucose and respiratory oxidative burst in the blood sample, and determined the growth performance and survival rate.

\subsection{Fish sampling}

The fish were anesthetized in water containing $0.1 \mathrm{~g} \mathrm{l}^{-1}$ benzocaine (Sigma-Aldrich, São Paulo, Brazil) until ventilatory movements ceased, and blood samples were drawn from the caudal vessels using syringes without anticoagulant. An aliquot was dispensed into heparinized microtubes and immediately used to measure respiratory oxidative burst, and the remaining sample was placed in microtubes containing the anticoagulant Glistab ${ }^{\circledR}$ (for glucose). The blood samples were centrifuged for $10 \mathrm{~min}$ at $3000 \times \mathrm{g}$ to obtain plasma, and the glucose levels were immediately determined.

\subsection{Preparation of diets}

To prepare the diets (Table 1 ), the macro and micro-ingredients were mixed together for $30 \mathrm{~min}$ in a mixer, and subsequently oil was slowly added into the feed and mixed for further 15 min. Boiling distilled water was subsequently slowly added to the diets

Table 1

Composition of the control and diets supplemented with $\beta$-glucans.

\begin{tabular}{llll}
\hline Feed composition & Control & BG01 & BG02 \\
\hline Moisture (g) & 120 & 120 & 120 \\
Gross protein (g) & 320 & 320 & 320 \\
Crude fat (g) & 45 & 45 & 45 \\
Crude fiber (g) & 90 & 90 & 90 \\
Mineral matter (g) & 120 & 120 & 120 \\
Calcium (g) & 25 & 25 & 25 \\
Phosphorus (mg) & 6000 & 6000 & 6000 \\
Vitamin C (mg) & 250 & 250 & 250 \\
Vitamin A (IU) & 8000 & 8000 & 8000 \\
Vitamin E (mg) & 120 & 120 & 120 \\
Zinc (mg) & 80 & 80 & 80 \\
$\beta$-glucan (g kg ${ }^{-1}$ ) & 0 & 0.1 & 0.1 \\
\hline
\end{tabular}

Values were expressed per kilogram of feed. and mixed for another $15 \mathrm{~min}$. The diets were pelleted using a chopper. The pellets were dried at $60^{\circ} \mathrm{C}$ for $18 \mathrm{~h}$ using a feed dryer and stored at $-20^{\circ} \mathrm{C}$ until further used.

\subsection{Preparation of S. agalactiae and experimental infection}

The S. agalactiae (1318LAPOA, Jaboticabal, São Paulo, Brazil) was identified after sequencing $16 \mathrm{~S}$ rDNA (similarity of 97\% with GenBank accession \#ATCC 7966). The bacteria were stored in TSB (Tryptic Soy Broth, HMedia) medium containing 30\% glycerol (sterile) at $-80^{\circ} \mathrm{C}$. Subsequently, an aliquot of $20 \mu \mathrm{l}$ was added into $5 \mathrm{ml}$ autoclaved TSB medium and incubated in a bacteriological incubator at $28{ }^{\circ} \mathrm{C}$, for $24 \mathrm{~h}$. Thereafter, $700 \mathrm{ml}$ autoclaved TSB medium was added, and the mixture was incubated again using the same procedure. This bacterial suspension was centrifuged at $12,000 \times \mathrm{g}$ for $20 \mathrm{~min}$, the supernatant was discarded, and subsequently PBS buffer $(0.01 \mathrm{M})$ with centrifugation steps of $12,000 \times \mathrm{g}$ for 20 min was used to wash the pellets. The bacterial concentration was determined based on the optical density (OD) at $600 \mathrm{~nm}$ (Unico spectrophotometer). The $\mathrm{OD}$ of the bacterial suspension was adjusted to 0.5 at $600 \mathrm{~nm}$, corresponding to $1.6 \times 10^{8}$ cells $/ \mathrm{ml}$. The fish designated to receive intraperitoneal injections were netted from the holding tanks and anesthetized. The mass was recorded, and the fish were treated with a $3 \mu \mathrm{lg}^{-1}$ intraperitoneal injection of S. agalactiae.

\subsection{Plasma glucose and respiratory oxidative burst assays}

The plasma glucose concentration was measured using the glucose oxidase method (Labtest kit ${ }^{\#} 84$, Sao Paulo, Brazil, http:// www.labtest.com.br/reagentes). The production of reactive oxygen species was measured using NBT (nitrotetrazolium blue chloride, Sigma-Aldrich, São Paulo, Brazil; "N6876), following the protocol of Sahoo et al. [10]. Immediately after bleeding, $100 \mu \mathrm{l}$ of heparinized blood was incubated with an equal volume of NBT buffer $(0.2 \%)$ at room temperature for 30 min. Thereafter, $1 \mathrm{ml}$ of dimethylformamide (DMF, Sigma-Aldrich, São Paulo, Brazil; ${ }^{\#} 227,056$ ) was added to the samples, followed by spectrophotometric assessment (Model Genesys 10S, Thermo Scientific, Madison, WI, USA) at $540 \mathrm{~nm}$ at room temperature.

\subsection{Growth performance and survival}

The initial weight of the fish was recorded during the random distribution into the tanks and the final weight data obtained after 30 days at sampling and before the immune challenge with a $3 \mu \mathrm{g} \mathrm{g}^{-1}$ intraperitoneal injection of $S$. agalactiae, as previously described. The growth performance parameters were calculated according to the following formula:

Weight gain $(\mathrm{g})=$ final weight $(\mathrm{g})$ - initial weight $(\mathrm{g})$

Feed Conversion Ratio = quantity of feed offered/weight gain

Specific Growth Rate $=100 \times($ ln final weight $-\ln$ initial weight $) /$ duration of the feeding

Survival $(\%)=($ final number of fish/initial number of fish $) \times 100$

\subsection{Statistical analyses}

All data were analyzed for normality (Cramer-von Mises) and homoscedasticity (Brown-Forsythe). Respiratory oxidative burst 
and plasma glucose were analyzed using two-way ANOVA (3 diets vs. 2 sampling points), followed by Duncan's Multiple Range Test. Growth performance was analyzed using one-way ANOVA, followed by Duncan's Multiple Range Test and each tank considered as experimental unit. $\mathrm{P}<0.05$ was used as the level of statistical significance in all analyses. Values in the text and figures are presented as the means \pm 1 standard error (S.E.) of the mean.

\subsection{Animal welfare statement}

The study was conducted according to the Ethical Principles in Animal Research of the National Council for the Control of Animal Experimentation and approved by the Ethics and Animal Welfare Committee of Universidade Estadual Paulista - UNESP (Protocol Number: 017,425/17).

\section{Results}

No mortality was observed during the feeding period. Fish fed with BG01 after the feeding trial had the highest value for respiratory burst activity, while the fish in the BG02 group had higher values than the control group $(P<0.05$, Fig. 1A). Nonetheless, after bacterial infection, the fish fed BG01 and BG02 diets showed a significant reduction compared with the sampling prior to infection. Further, after bacterial infection the respiratory burst activity remained higher in fish fed the BG01 diet $(P<0.05$, Fig. 1A). Plasma glucose was lower in fish fed the BG02 diet after the feeding trial $(P<0.05$, Fig. 1B). However, after bacterial infection, the fish fed control and BG01 diets showed decreased plasma glucose levels compared with the sampling prior to infection. After infection, the fish in the BG02 group had higher levels compared with those in the BG01.

No significant differences were observed in the initial weight of the fish $(P>0.05$, Table 2). However, fish fed the BG02 diet displayed improved $(\mathrm{P}<0.05)$ growth performance, including final weight, weight gain and specific growth rate. Furthermore, tilapia fed the BG01 diet had a significantly higher specific growth rate compared with the control treatment. Although the feed conversion ratio of control group (1.8) was approx. 25\% higher compared to BG01 and BG02 ( 1.4), no significant differences were observed

A

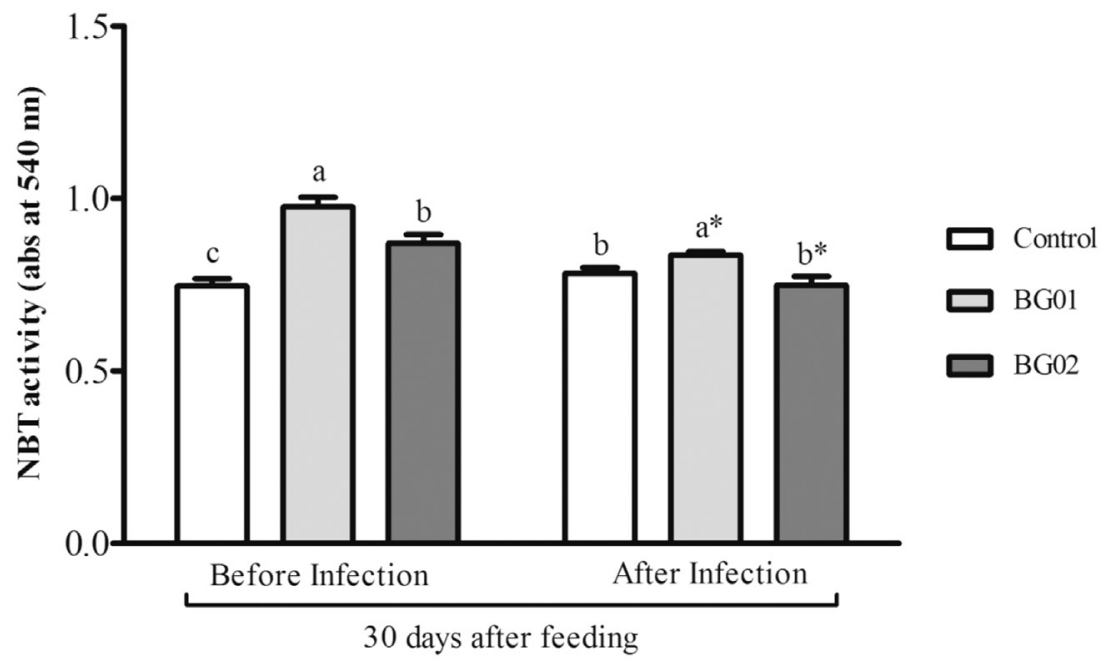

B

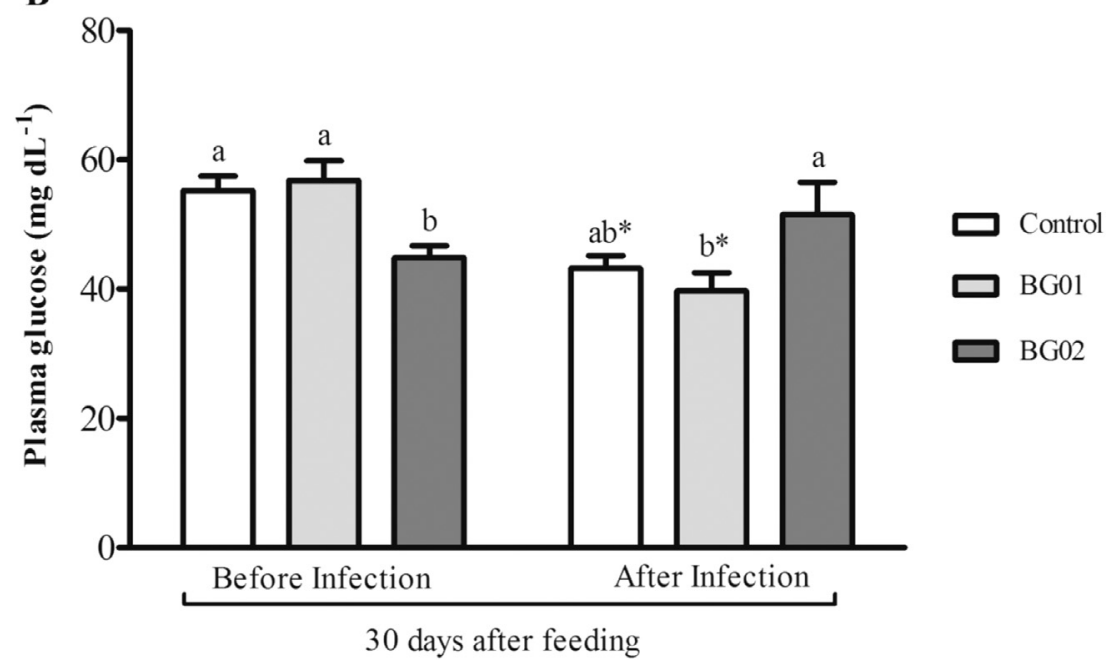

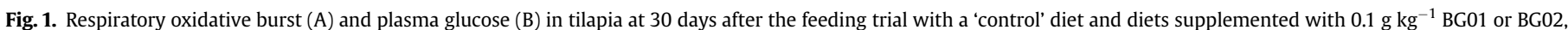

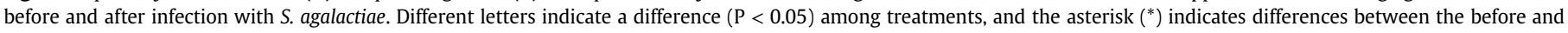
after injection samples within in the same treatment. The values are presented as the means \pm 1 standard error (S.E.), $\mathrm{N}=20$. 
Table 2

Growth performance and survival rate of Nile tilapia fed control and diets supplemented with $0.1 \mathrm{~g} \mathrm{~kg}^{-1}$ BG01 or BG02.

\begin{tabular}{llll}
\hline & \multicolumn{3}{l}{ Experimental diets } \\
\cline { 2 - 4 } & Control & BG01 & BG02 \\
\hline Initial weight $(\mathrm{g})$ & $192.06 \pm 3.53 \mathrm{a}$ & $179.47 \pm 4.57 \mathrm{a}$ & $192.99 \pm 0.67 \mathrm{a}$ \\
Final weight $(\mathrm{g})$ & $254.68 \pm 1.28 \mathrm{~b}$ & $256.50 \pm 6.97 \mathrm{~b}$ & $278.16 \pm 1.05 \mathrm{a}$ \\
Weight gain $(\mathrm{g})$ & $62.62 \pm 4.82 \mathrm{~b}$ & $77.02 \pm 2.40 \mathrm{ab}$ & $85.31 \pm 1.58 \mathrm{a}$ \\
Feed Conversion Ratio & $1.85 \pm 0.17 \mathrm{a}$ & $1.40 \pm 0.01 \mathrm{a}$ & $1.36 \pm 0.03 \mathrm{a}$ \\
Specific Growth Rate & $0.94 \pm 0.07 \mathrm{~b}$ & $1.19 \pm 0.006 \mathrm{a}$ & $1.21 \pm 0.02 \mathrm{a}$ \\
Survival rate $(\%)$ & 53.30 & 95.00 & 90.47 \\
\hline
\end{tabular}

Data with different letters are significantly different from each other $(\mathrm{P}<0.05)$. The values are presented as the means \pm 1 standard error (S.E.).

$(\mathrm{P}=0.0558$, Table 2$)$. At the end of the trial, the survival rate was higher in fish fed BG01 and BG02 diets compared with the control group $(\mathrm{P}<0.05$, Table 2$)$.

\section{Discussion}

Recently, the strengthening of the fish immune system through dietary additives, such as $\beta$-glucans, has been target of great interest $[11,12]$. Despite extensive studies, few reports have explored the diversity of source and biotechnical methods to extract $\beta$-glucans. Here, we tested two different $\beta$-glucan molecules, and the results showed that these molecules generated responses of different magnitudes on fish immunity and growth. Furthermore, in the near future we could explore it for distinct application and approaches to optimize the benefits of $\beta$-glucan molecules in aquaculture industry.

Respiratory oxidative burst is the rapid release of reactive oxygen species produced from macrophages and neutrophils after contact with foreign particles and plays an essential role in the control of host immune responses and resistance to pathogens [13]. Here, we showed that both $\beta$-glucans enhanced respiratory oxidative burst, consistent with similar studies on tilapia and other species [14-16]. However, fish fed BG01 had higher respiratory oxidative burst compared with the BG02 group. We suggested that the BG01 molecule exhibits higher immunostimulation compared with BG02. We also observe a decrease in respiratory oxidative burst in fish fed both $\beta$-glucans after bacterial infection. This reduction could reflect the migration of bloodstream leukocytes to sites of infection induced through hemostasis. This finding confirms the effects of $\beta$-glucans on the immune response, and these compounds could increase bacterial resistance, consistent with the higher survival rate observed in fish fed $\beta$-glucans (95 and $90.47 \%$, BG01 and BG02, respectively) compared with the control (53.3\%). Selvaraj et la [17]. observed the dramatically reduced survival of Aeromonas hydrophila in vitro after exposure to macrophages obtained from fish with enhanced oxygen burst activity.

After 30 days of feeding with BG02, the fish showed lower plasma glucose levels compared with the control and the BG01 group. Additionally, we also observed improvements in the growth performance of fish fed BG02. We hypothesized that BG02 might provide increased prebiotic effects (previous unpublished studies) $[1,2]$ and decreased gut inflammation and consequently cortisol and glucose levels (see discussion below) [18]. This event contributed to energy conservation, increased feed efficiency and consequently enhanced growth. Although the relationship of metabolic cost to mounting an immune response is not clear (see Zanuzzo et al. [19]), BG02 also exhibited lower immunostimulation compared with BG01, suggesting more energy for growth. Furthermore, fish fed with BG02 showed increased plasma glucose levels after bacterial infection. Currently, there is no clear explanation for this result, however these observation could be associated with the modulation trigged by BG02 on the hypothalamus-pituitary-interrenal axis and cortisol/glucose release as also recent observed by Montoya et al. [20]. Further investigations are being designed to address this issue.

Several studies have demonstrated the immunostimulatory effect of dietary $\beta$-glucan supplementation in fish [15,21-25], but the results addressing the growth performance are controversial [6], as this effect might result from the treatment dosage, feeding duration, water temperature, species examined and administration route [4]. Here, we showed that Nile tilapia fed $0.1 \mathrm{~g} \mathrm{~kg}^{-1} \beta$-glucan for 30 days exhibited improved growth performance, and BG02 displayed higher growth parameters compared with the control and the BG01 group. Although the feed conversion ratio has not been significantly different, the control group was (1.8) approx. 25\% higher compared to BG01 and BG02 ( 1.4). Some reports have demonstrated that dietary $\beta$-glucans promote the improvement of intestinal microbes and reduce the number of diseases/inflammations resulting from pathogenic bacteria in fish [1,2,26,27]. One hypothesis is that the positive effects on intestinal microbial $\beta$ glucan administration reduce gut inflammation and improve growth performance [6,28]. However, further studies are needed to identify the factors responsible for the elevated growth observed after $\beta$-glucan administration.

These results showed that $\beta$-glucans have different magnitudes of effects on growth performance and the immune response. Specifically, even with a similar survival rate, the BG01 showed higher immunostimulation than BG02. However, BG02 improved the growth performance. Vetvicka and Oliveira [29] reported different intensity responses in dogs using these same $\beta$-glucan molecules. Based on the above statements, we conclude that these $\beta$-glucan molecules can be used for different approaches, and these compounds are of great interest to the aquaculture industry. However additional experiments are needed to elucidate/clarify the differences between BG01 (immunomodulator action) and BG02 (prebiotic effect) observed in the present study.

In conclusion, the results of the present study provide additional evidence that $\beta$-glucans improve the bacterial resistance and growth performance of Nile tilapia. In addition, these findings show the great potential/plasticity of $\beta$-glucan molecules and encourage further research on the enhancement and development of new $\beta$ glucan molecules for different applications. Moreover, we confirmed prophylactic care using natural dietary supplements as a sustainable and environmentally friendly approach in modern aquaculture.

\section{Acknowledgments}

The authors would like to thank Biorigin for the $\beta$-glucan donation and the intellectual and financial support. The authors would also like to thank Trouw Nutrition (Nutreco Company) for assistance with the diet preparation.

\section{Appendix A. Supplementary data}

Supplementary data related to this article can be found at http:// dx.doi.org/10.1016/j.fsi.2017.06.059.

\section{References}

[1] D. Carbone, C. Faggio, Importance of prebiotics in aquaculture as immunostimulants. Effects on immune system of Sparus aurata and Dicentrarchus labrax, Fish. Shellfish Immunol. 54 (2016) 172-178.

[2] N. Akhter, B. Wu, A.M. Memon, M. Mohsin, Probiotics and prebiotics associated with aquaculture: a review, Fish. Shellfish Immunol. 45 (2) (2015) $733-741$. 
[3] D.K. Meena, P. Das, S. Kumar, S.C. Mandal, A.K. Prusty, S.K. Singh, M.S. Akhtar B.K. Behera, K. Kumar, A.K. Pal, S.C. Mukherjee, Beta-glucan: an ideal immunostimulant in aquaculture (a review), Fish. Physiol. Biochem. 39 (3) (2013) 431-457.

[4] R.A. Dalmo, J. Bogwald, Beta-glucans as conductors of immune symphonies, Fish. Shellfish Immunol. 25 (4) (2008) 384-396.

[5] L. Barsanti, V. Passarelli, V. Evangelista, A.M. Frassanito, P. Gualtieri, Chemistry, physico-chemistry and applications linked to biological activities of betaglucans, Nat. Prod. Rep. 28 (3) (2011) 457-466.

[6] M.S. Aramli, B. Kamangar, R.M. Nazari, Effects of dietary beta-glucan on the growth and innate immune response of juvenile Persian sturgeon, Acipenser persicus, Fish. Shellfish Immunol. 47 (1) (2015) 606-610.

[7] H.S. Goodridge, A.J. Wolf, D.M. Underhill, Beta-glucan recognition by the innate immune system, Immunol. Rev. 230 (2009) 38-50.

[8] G.D. Brown, S. Gordon, Fungal beta-glucans and mammalian immunity, Immunity 19 (3) (2003) 311-315.

[9] D. Akramiene, A. Kondrotas, J. Didziapetriene, E. Kevelaitis, Effects of betaglucans on the immune system, Med. Lith. 43 (8) (2007) 597-606.

[10] P.K. Sahoo, J. Kumari, B.K. Mishra, Non-specific immune responses in juveniles of Indian major carps, J. Appl. Ichthyol. 21 (2) (2005) 151-155.

[11] M. Bagni, N. Romano, M.G. Finoia, L. Abelli, G. Scapigliati, P.G. Tiscar, M. Sarti, G. Marino, Short- and long-term effects of a dietary yeast beta-glucan (Macrogard) and alginic acid (Ergosan) preparation on immune response in sea bass (Dicentrarchus labrax), Fish. Shellfish Immunol. 18 (4) (2005) 311-325.

[12] Y.-S. Wu, T.-Y. Tseng, F.-H. Nan, Beta-1,3-1,6-glucan modulate the nonspecific immune response to enhance the survival in the Vibrio alginolyticus infection of Taiwan abalone (Haliotis diversicolor supertexta), Fish. Shellfish Immunol. 54 (2016) 556-563.

[13] B.M. Babior, R.S. Kipnes, J.T. Curnutte, Biological defense mechanisms - production by leukocytes of superoxide a potential bactericidal agent, J. Clin. Invest. 52 (3) (1973) 741-744.

[14] W. Sirimanapong, A. Adams, E.L. Ooi, D.M. Green, D.K. Nguyen, C.L. Browdy, B. Collet, K.D. Thompson, The effects of feeding immunostimulant beta-glucan on the immune response of Pangasianodon hypophthalmus, Fish. Shellfish Immunol. 45 (2) (2015) 357-366.

[15] M.E. El-Boshy, A.M. El-Ashram, F.M. AbdelHamid, H.A. Gadalla, Immunomodulatory effect of dietary Saccharomyces cerevisiae, beta-glucan and laminaran in mercuric chloride treated Nile tilapia (Oreochromis niloticus) and experimentally infected with Aeromonas hydrophila, Fish. Shellfish Immunol. 28 (5-6) (2010) 802-808.

[16] J.B. Jorgensen, B. Robertsen, Yeast beta-glucan stimulates respiratory burst activity of Atlantic salmon (Salmo salar L) macrophages, Dev. Comp. Immunol. 19 (1) (1995) 43-57.

[17] V. Selvaraj, K. Sampath, V. Sekar, Adjuvant and immunostimulatory effects of beta-glucan administration in combination with lipopolysaccharide enhances survival and some immune parameters in carp challenged with Aeromonas hydrophila, Vet. Immunol. Immunopathol. 114 (1-2) (2006) 15-24.

[18] S.E. Wendelaar Bonga, The stress response in fish, Physiol. Rev. 77 (3) (1997) 591-625.

[19] F.S. Zanuzzo, E.C. Urbinati, G.W. Nash, A.K. Gamperl, Steelhead trout Oncorhynchus mykiss metabolic rate is affected by dietary Aloe vera inclusion but not by mounting an immune response against formalin-killed Aeromonas salmonicida, J. Fish. Biol. 87 (1) (2015) 43-53.

[20] L.N. Franco Montoya, T.P. Martins, R.Y. Gimbo, F.S. Zanuzzo, E.C. Urbinati, BetaGlucan-induced cortisol levels improve the early immune response in matrinxa (Brycon amazonicus), Fish. Shellfish Immunol. 60 (2017) 197-204.

[21] V.R. Reque, J.R.E, de Moraes, M.A.D. Belo, F.R. de Moraes, Inflammation induced by inactivated Aeromonas hydrophila in Nile tilapia fed diets supplemented with Saccharomyces cerevisiae, Aquaculture 300 (1-4) (2010) $37-42$.

[22] T.L. Welker, C. Lim, M. Yildirim-Aksoy, P.H. Klesius, Use of diet crossover to determine the effects of beta-glucan supplementation on immunity and growth of Nile Tilapia, Oreochromis niloticus, J. World Aquac. Soc. 43 (3) (2012) $335-348$.

[23] R.A. Shelby, C. Lim, M. Yildirim-Aksoy, T.L. Welker, P.H. Klesius, Effects of yeast Oligosaccharide diet supplements on growth and disease resistance in juvenile Nile Tilapia, Oreochromis niloticus, J. Appl. Aquac. 21 (1) (2009) 61-71.

[24] W.S. Wang, S.W. Hung, Y.H. Lin, C.Y. Tu, M.L. Wong, S.H. Chiou, M.T. Shieh, The effects of five different glycans on innate immune responses by phagocytes of hybrid tilapia and Japanese eels Anguilla japonica, J. Aquat. Anim. Health 19 (1) (2007) 49-59.

[25] R. Whittington, C. Lim, P.H. Klesius, Effect of dietary beta-glucan levels on the growth response and efficacy of Streptococcus iniae vaccine in Nile tilapia, Oreochromis niloticus, Aquaculture 248 (1-4) (2005) 217-225.

[26] H. Kuhlwein, M.J. Emery, M.D. Rawling, G.M. Harper, D.L. Merrifield, S.J. Davies, Effects of a dietary beta-(1,3)(1,6)-D-glucan supplementation on intestinal microbial communities and intestinal ultrastructure of mirror carp (Cyprinus carpio L.), J. Appl. Microbiol. 115 (5) (2013) 1091-1106.

[27] H. Do Huu, H.M. Sang, N.T. Thanh Thuy, Dietary $\beta$-glucan improved growth performance, Vibrio counts, haematological parameters and stress resistance of pompano fish, Trachinotus ovatus Linnaeus, 1758, Fish. Shellfish Immunol. 54 (2016) 402-410.

[28] Q.H. Ai, K.S. Mai, L. Zhang, B.P. Tan, W.B. Zhang, W. Xu, H.T. Li, Effects of dietary beta-1,3 glucan on innate immune response of large yellow croaker, Pseudosciaena crocea, Fish. Shellfish Immunol. 22 (4) (2007) 394-402.

[29] V. Vetvicka, C. Oliveira, $\beta(1-3)(1-6)-D$-glucans modulate immune status and blood glucose levels in dogs, Brit. J. Pharm. Res. 4 (8) (2014) 981-991. 